\title{
Diffuse and localized deformation of a porous Vosges sandstone in true triaxial conditions
}

\author{
Cyrille-B. Couture ${ }^{1, *}$ and Pierre Bésuelle ${ }^{1}$ \\ ${ }^{1}$ Univ. Grenoble Alpes, CNRS, Grenoble INP, 3SR, 38000 Grenoble, France
}

\begin{abstract}
This work presents an experimental study on the diffuse and localized deformation mechanisms of a high porosity (20\%) Vosges sandstone (Eastern France) subjected to different stress paths in the deviatoric plane. The experimental campaign was performed using a high pressure true triaxial apparatus (TTA) in which the three principal stresses are independently controlled. A series of 10 quasi-static, monotonous loading tests was performed at 2 constant mean stresses, in the brittle-ductile transition regime, and at five prescribed Lode angles, from axisymmetric compression (ASC) to axisymmetric extension (ASE), as a measure of the deformation mode. The failure surface in each deviatoric plane and changes in macroscopic measurements, such as deformation band angles tracked by full field digital image correlation (DIC) technology, indicate a clear effect of the Lode angle on a transition between the brittle and ductile regime, independent from the mean stress level.
\end{abstract}

\section{Introduction}

It is of clear interested in rock mechanics to identify deformation mechanisms which can lead to global failure of a confined rock mass. In porous sandstone, a predominant and well-studied mechanism leading to failure is the development of shear localization in planar bands of finite thickness. Localization patterns involving single or conjugated deformation bands have been observed in stressed rock formations in the field [1], as well as in in laboratory settings [2]. In these controlled and monitored environment, it is possible to reproduce and study the various field conditions which influence the development of deformation bands.

In this context, experimental studies exploring the effect of mechanical loading paths on shear localization are of importance in the field of applied rock mechanics. However, previous experimental campaigns which address the influence of stress states on the deformation and strength of rock specimens have been, for the most part, performed using conventional triaxial systems [3], limiting available stress paths to ones where two of the principal stresses remain identical during monotonic loading. It results that models describing the intrinsic behavior of cohesive geomaterials rely heavily on experimental data which typically follow axisymmetric conditions, leaving a broad spectrum of the deviatoric plane unexplored.

Following the seminal work of Mogi [4], experimental equipments which enable independent control of the three principal stresses $\left(\sigma_{1} \geq \sigma_{2} \geq \sigma_{3} \geq 0\right)$, so called truetriaxial apparatus (TTA), have been designed to access all possible stress states in the principal stress space, within

*e-mail: cyrille.couture@3sr-grenoble.fr allowable pressure range of the system. This type of apparatus has been used in the past for polyaxial compression tests to measure the effect of the intermediate principal stress on rocks with various mineral composition (e.g. [4-7]). More recently, a study by Ingraham et al. [8] investigates the independent effect of stress invariants on the mechanical response of a porous sandstone in a series of independent loading paths in the deviatoric plane. Ma et al. [9] have also followed a similar methodology, exploring the effect of the Lode angle at constant minor principal stress in two porous sandstones. These research have consistently shown a measurable effect of the Lode angle on failure and the development of post-mortem localization patterns. However, experimental data on the subject remains scarce.

This article proposes to further study the phenomenon of strain localization under polyaxial stress conditions through a series of TTA experiments, with imposed constrains on the stress invariants. In addition to the analysis of global mechanical and deformation measurements, the design of the testing apparatus made it possible to follow the evolution of strain localization using full field measurement by digital image correlation during the deviatoric loading phase.

\section{Material and Methods}

\subsection{Sample characterization}

The selected material is a red Vosges sandstone retrieved from the Woustwiller quarry, Eastern France. Its physical characteristics were reported in previous experimental campaigns exploring localization in soft porous sandstone 
Table 1. Mineral characterization of Vosges Sandstone [10]

\begin{tabular}{ll}
\hline mineral composition & $93 \%$ quartz \\
& $5 \%$ microcline \\
& $2 \%$ mica and kaolinite \\
porosity & $21 \%$ \\
grain size & $150-450 \mu \mathrm{m}$ \\
mean grain size & $300 \mu \mathrm{m}$ \\
\hline
\end{tabular}

under axisymmetric [10] and plane strain [11] loading conditions. Other studies on sandstone from the same Triassic rock formation in the Vosges region suggest a weak mechanical anisotropy in this type of bedded sedimentary rocks [12]. The focus of this study is on a single material orientation of $90^{\circ}$ (horizontal bedding).

The arithmetic mean of connected porosity, measured on each sample by progressive vaccum water saturation, was $21 \% \pm 1$. It is similar to what was previously recorded for specimens prepared from the same source of excavated material.

\subsection{True Triaxial Apparatus (TTA)}

The TTA used in the scope of this work has been developed at laboratoire 3SR to test rock specimen in biaxial and polyaxial loading conditions [14]. It can accommodate machined prismatic samples of $50 \times 30 \times 25 \mathrm{~mm}^{3}$ inside a specially fabricated urethane membrane (figure 1). The apparatus was designed to apply isotropic confinement of up to $100 \mathrm{MPa}$ by increasing the fluid pressure in the hosting chamber where the isolated specimen is mounted. The stress deviators, in the major and intermediate principal stress directions, are applied by the means of hydraulic pistons in contact with the sample surface. For the specified sample dimensions, deviatoric stresses can reach approximately $500 \mathrm{MPa}$ in both directions.

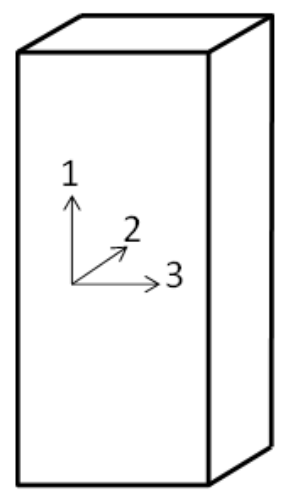

Fig. 1. Prismatic specimen deformed in the true triaxial apparatus, with the associated spatial directions

In the intermediate principal direction, the TTA is equipped with a sapphire view-port enabling the acquisition of digital images using a Nikon800E equipped with a $36 \mathrm{MPx}$ sensor, allowing a spacial resolution of $7 \mathrm{mi}$ crons/pixel. With calibrated settings for noise and vibration reduction, photographs can be taken at a regular time intervals of 1 image every 3 seconds. To perform incremental digital image correlation (DIC) on the set of recorded images, a fine monochromatic speckle is applied on the sample surface visible through the sapphire viewport. This enables full-field deformation measurements in the 1-3 spacial directions. In the out-of-plane intermediate (2) direction, strain gauges are used to measure deformation in the center of the specimen.

\subsection{Loading procedure}

In the series of experiments on 10 identically prepared samples, the first and third Lode-invariants of the stress tensor remained constant during the deviatoric loading phase. We define these invariants, in terms of principal stresses, as follow:

$$
\begin{aligned}
\sigma_{m} & =\frac{1}{3}\left[\sigma_{1}+\sigma_{2}+\sigma_{3}\right] \\
\tau_{o c t} & =\frac{1}{3}\left[\left(\sigma_{1}-\sigma_{2}\right)^{2}+\left(\sigma_{1}-\sigma_{3}\right)^{2}+\left(\sigma_{2}-\sigma_{3}\right)^{2}\right]^{1 / 2} \\
\theta & =\arctan \left[\sqrt{3} \frac{\sigma_{2}-\sigma_{3}}{\left(\sigma_{1}-\sigma_{2}\right)+\left(\sigma_{1}-\sigma_{3}\right)}\right]
\end{aligned}
$$

where $\sigma_{m}$ is the mean stress; $\tau_{o c t}$ is the octahedral stress which measures the stress departure from the isotropic state; and $\theta$ is the Lode angle in the deviatoric plane. It spans from $0^{\circ}$ in axisymmetric compression (ASC) to $60^{\circ}$ in axisymmetric extension (ASE).

A consistent procedure was followed during the loading phase of each experiment: once the sample is installed and the apparatus assembled, an alignment phase is initiated to insure good contact between the hard platens, loaded by the hydraulic pistons, and the specimen; a subsequent isotropic loading phase consists of increasing the cell pressure, at a rate of $2 \mathrm{MPa} / \mathrm{min}$ until the prescribed mean stress is reached; finally the deviatoric loading phase consist of monotonically increasing the octahedral stress, resolved on the integral of the specimen boundary, by controlling the intermediate and minor principal stresses as functions of the major principal stress. This procedure, regulated by a PID controller, insures the mean stress and Lode angle remained constant for the entire loading phase.

\section{Experimental Results}

Guided by the study of Bésuelle et al. [10] in which axisymmetric compression loading tests were performed on Vosges sandstone, the range of mean stress was selected so as to reproduce deformation characteristics during failure associated with the brittle-ductile transition regime. The experimental campaign consisted of testing 10 Vosges sandstone specimens at five Lode angles (0, 15, 30, 45 and $\left.60^{\circ}\right)$ and at the two constant mean stresses of 60 and $90 \mathrm{MPa}$.

The resulting octahedral stress-strain and volumetric curves, shown in Figure 2, were corrected using displacement measurements from DIC at the sample boundary in directions 1 and 3, while strain gauges are used in direction 2. The comparison of mechanical curves indicates 

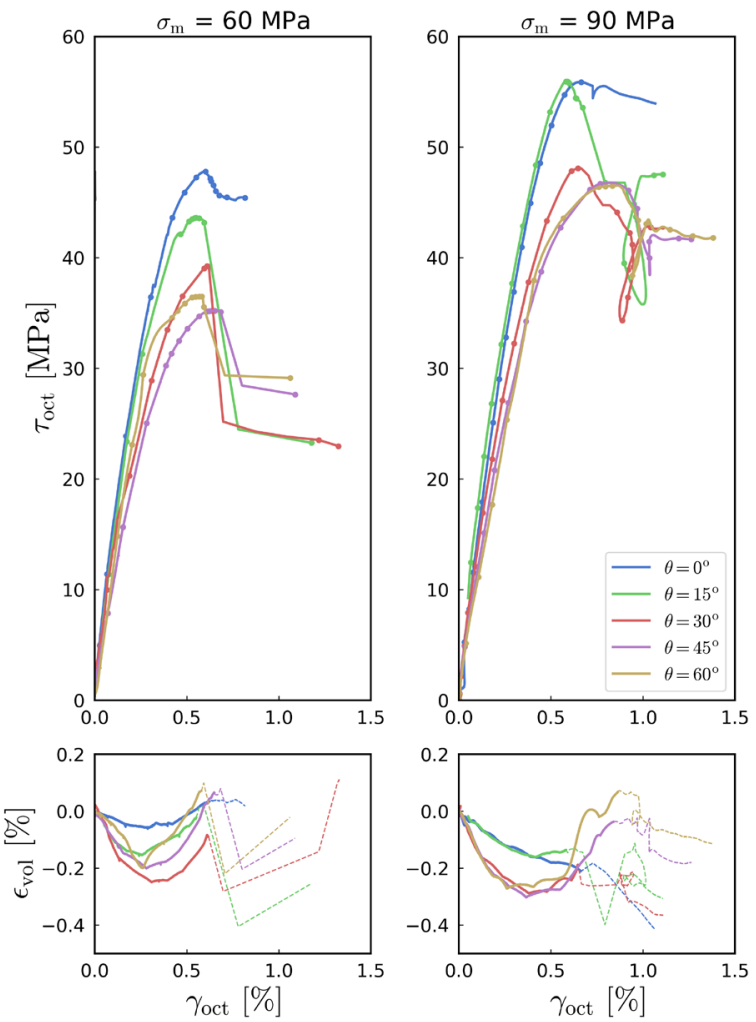

Fig. 2. Stress-strain and volumetric curves as a function of octahedral shear stress $\left(\gamma_{o c t}\right)$, analogue to $\tau_{o c t}$. The dashed lines shows volumetric strains in the post peak regime

that, irrespective of the Lode angle, the increase in mean stress, from $60 \mathrm{MPa}$ to $90 \mathrm{MPa}$, induces an increase in the peak strength of the material: a $22 \%$ increase for a Lode angle of $0^{\circ}$ was measured and a more pronounced increase, greater then $30 \%$, at higher Lode angles (see figure $3 \mathrm{a}$ ).

A change in the mechanical response is also observed for experiments at the same mean stress level: in both series of 5 tests, we observe a decrease in the peak stress with increasing Lode angle. This variation is however nonlinear as most of the transition appears to be occurring at lower Lode angles (from 0 to $30^{\circ}$ ); for Lode angles of 30 , 45 and $60^{\circ}$, the peak strength is almost constant. In figure 2 we observe that the transition appears to be more progressive at $60 \mathrm{MPa}$ and abrupt at $90 \mathrm{MPa}$.

At a mean stress of $90 \mathrm{MPa}$, this change in regime is emphasized by two other global observations: the prepeak hardening phase for tests at a $\sigma_{m}$ of $90 \mathrm{MPa}$ and $\theta$ of $0^{\circ}$ and $15^{\circ}$ are comparable and significantly different from the trend observed at higher Lode angles; in these two tests the volumetric strain evolution is also distinct from other tests, where a more progressive compactancy and no global sign of dilatancy during the hardening phase is observed (see figure 2).

Local representation of deviatoric strain magnitude in the 1-3 plane enabled the identification of localization and its evolution. This representative value is used to characterize the predominant band angle during the transition from a hardening to a softening regime or uncontrolled


Fig. 3. Evolution of the peak stress (a), and the band angle (b) with the Lode angle at the 2 mean stresses of 60 and $90 \mathrm{MPa}$.

fracturing. Figure 4 shows a 2D map of the square norm of the 2 dimensional deviatoric strain tensor U-I, where U is the right stretch tensor, " $\wedge$ " denotes the deviatoric part and $\mathrm{I}$ is the identity matrix. This field derived from the displacement field obtained by 2D DIC, is a good indicator of the concentration of the shear deformation.

The observed band angle $(\beta)$, as it is fully developed across the sample, is known to vary with the degree of ductility in the mode of deformation experienced by the specimen. It is here defined as the angle between the most compressive principal stress direction $\left(\sigma_{1}\right)$ and the shear bands. Figure $3 \mathrm{~b}$ shows its evolution with the mean stress and the Lode angle. A decrease of the band angle with increasing Lode angle and an increase with the mean stress was observed. This trend is related to observations in peak stress variation.

At a Lode angle of $15^{\circ}$ and mean stress of $90 \mathrm{MPa}$, although the mechanical response of the test is comparable to the test at a Lode angle of $0^{\circ}$, the recorded damage patterns is not as diffuse and is more consistent with ones observed in tests at higher Lode angle, where large deformation occurs in a single shear band.

\section{Discussion and Conclusion}

The results from this series of stress controlled experiments present possible effect of various stress paths, expressed by different Lode angles, on the brittle to ductile transition for isotropic porous rocks. This suggests that, in addition to the mean stress level $\left(\sigma_{m}\right)$, the mode of deformation induced by the distribution of stress in the intermediate and minor principal directions, expressed by the Lode angle, has significant and non-linear repercussions on peak strength and failure mode.

A failure surface taking into account variations of strength with the Lode angle will be affected by the transition in the peak stress, resulting in a change of curvature 


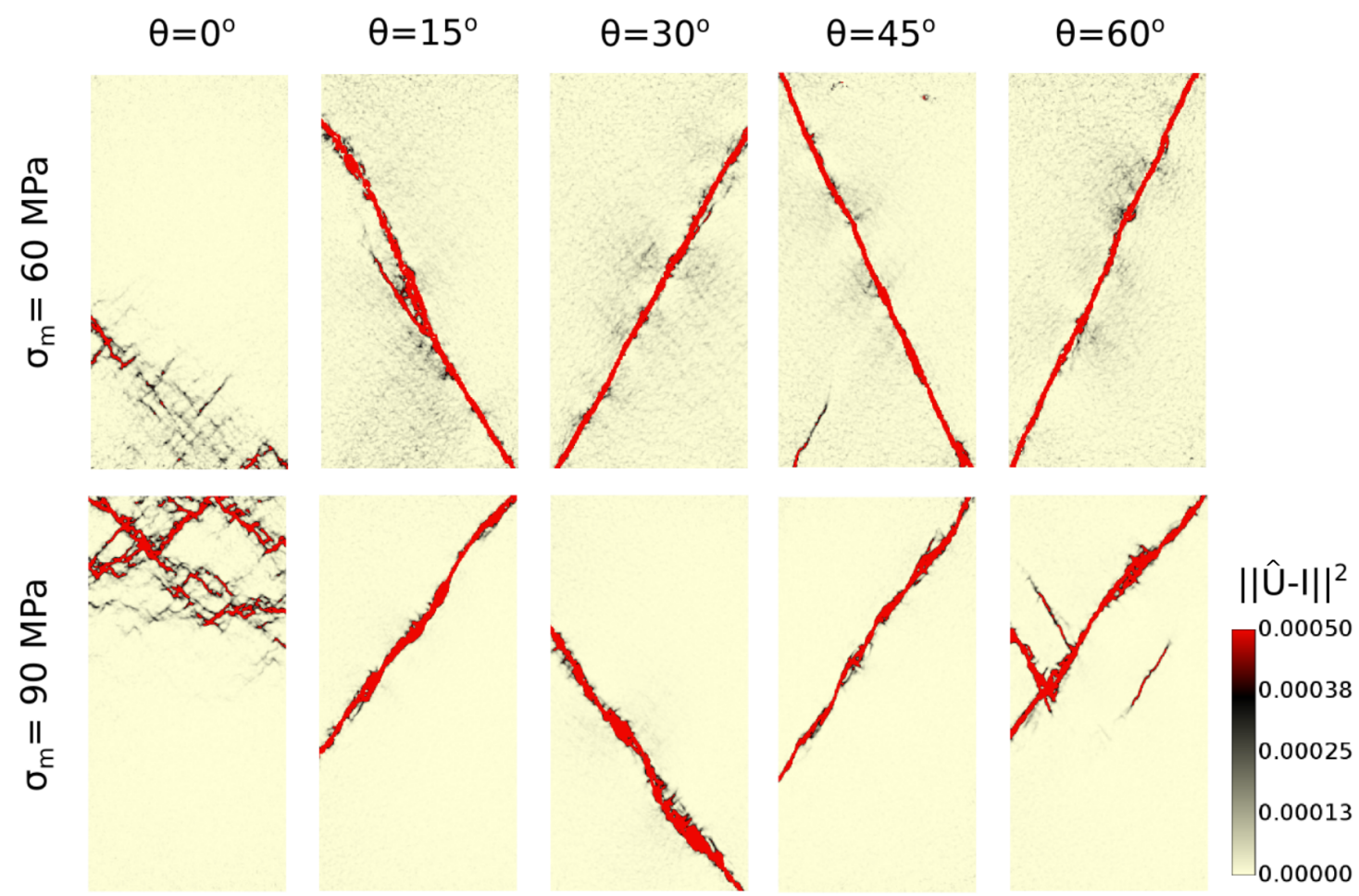

Fig. 4. Map of local deviatoric strain around the maximum stress for the 10 samples tests during this experimental campaign.

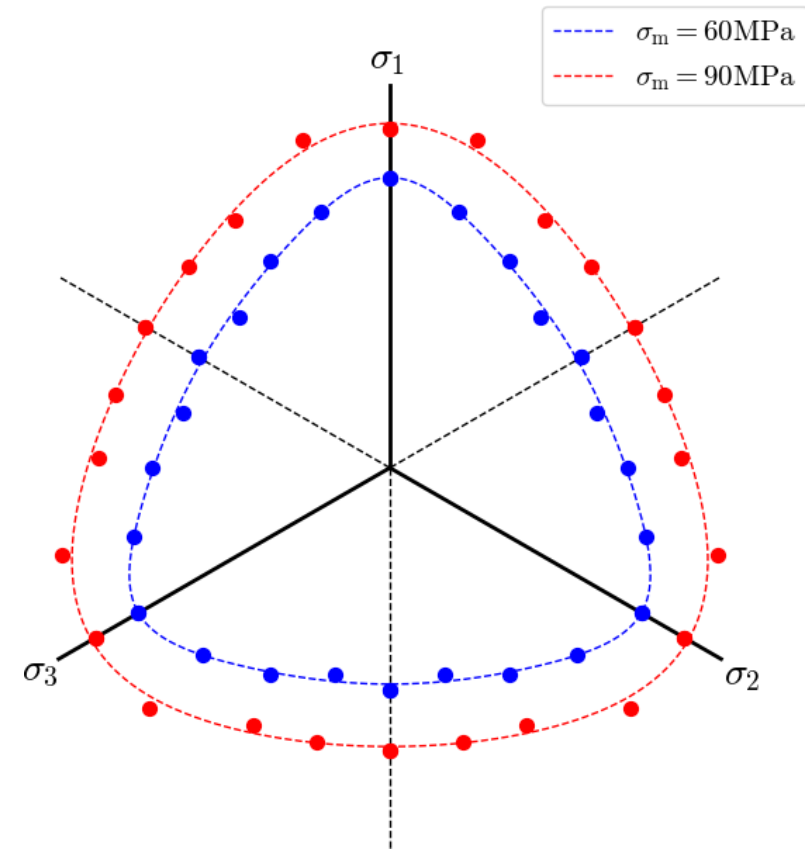

Fig. 5. Experimental data of octahedral peak stress and VanEekelen failure surface in the deviatoric plane. The hexagonal sections reflects the symmetries for isotropic material with commutable principal stress directions

of the failure surface for the range of stress states in the brittle-ductile transition regime. A generic failure surface can be fitted by data points in each deviatoric plane using the Van-Eekelen criterion [15] (Figure 5 ):

$$
\tau_{o c t}(\theta)=A(1-\zeta \sin (3 \theta))^{n}
$$

where $\mathrm{A}$ is a scaling parameter, $\mathrm{n}$ is imposed at -0.229 to preserve convexity of the failure surface and $\zeta$, an indicator of the degree of curvature, is optimized using a least-square minimization method over the 5 data points at each $\sigma_{m}$. At $\sigma_{m}=60 \mathrm{MPa}$ and $90 \mathrm{MPa}, \zeta=-0.570$ and -0.432 respectively. Higher values of $\zeta$ indicates a roundness which tend towards constant radius of $\tau_{o c t}$ for higher $\sigma_{m}$.

To conclude, experiments under polyaxial loading paths coupled with full field 2D DIC techniques proved to enrich our understanding of failure in high porosity sandstone. Experimental measurements done in the scope of this research provide a reference to evaluate and expend bifurcation theory as a way to predict failure and failure mode in rocks.

\section{References}

[1] H. Fossen, R.A. Schultz, Z.K. Shipton \& K. Mair, Deformation bands in sandstone: a review. Journal of the Geological Society 164, 755-769 (2007).

[2] T. Wong \& P. Baud, The brittle-ductile transition in porous rock: A review. Journal of Structural Geology 44, 25-53 (2012).

[3] M. S. Paterson \& T. F. Wong, Experimental Rock Deformation-The Brittle Field, 2nd ed., Springer, New York (2005).

[4] K. Mogi, Effect of the triaxial stress system on the failure of dolomite and limestone. Tectonophysics 11, 111-127 (1971). 
[5] M. Takahashi \& H. Koide, Effect of the intermediate principal stress on strength and deformation behavior of sedimentary rocks at the depth shallower than $2000 \mathrm{~m}$. in (International Society for Rock Mechanics, 1989).

[6] W. Wawersik, L. Carlson, D. Holcomb \& R. Williams, New method for true-triaxial rock testing. International Journal of Rock Mechanics and Mining Sciences 34, 330 (1997).

[7] B. Haimson \& C. Chang, A new true triaxial cell for testing mechanical properties of rock, and its use to determine rock strength and deformability of Westerly granite. International Journal of Rock Mechanics and Mining Sciences 37, 285-296 (2000).

[8] M. Ingraham, K. Issen \& D. Holcomb, Response of Castlegate sandstone to true triaxial states of stress. Journal of Geophysical Research: Solid Earth 118, 536-552 (2013).

[9] X. Ma \& B.C. Haimson, Failure characteristics of two porous sandstones subjected to true triaxial stresses. Journal of Geophysical Research: Solid Earth 121, 6477-6498 (2016).

[10] P. Bésuelle, J. Desrues \& S. Raynaud, Experimental characterisation of the localisation phenomenon inside a Vosges sandstone in a triaxial cell. International Journal of Rock Mechanics and Mining Sciences 37, 1223-1237 (2000).

[11] P. Bésuelle \& P. Lanatà, A New True Triaxial Cell for Field Measurements on Rock Specimens and Its Use in the Characterization of Strain Localization on a Vosges Sandstone During a Plane Strain Compression Test. Geotechnical Journal 39, 879-890 (2016).

[12] A. Millien, Comportement anisotrope du grès des Vosges: Élastoplasticité, localization de la rupture [in French], PhD thesis, Univ. Joseph Fourier, Grenoble, France (1993).

[13] J.F. Labuz \& J.M. Bridell, Reducing Frictional Constraint in Compression Testing Through Lubrication. International Journal of Rock Mechanics and Mining Sciences 30, 451-455 (1993).

[14] P. Bésuelle \& S. Hall, Characterization of the strain localization in a porous rock in plane strain condition using a new true-triaxial apparatus. in Advances in bifurcation and degradation in geomaterials 345-352 (Springer, 2011).

[15] H.A.M. Van Eekelen, Isotropic yield surfaces in three dimensions for use in soil mechanics. International Journal for Numerical and Analytical Methods in Geomechanics 4, 89-101 (1980). 